\title{
Optimized Modular window as a sustainable and industrialized solution for indoor daylighting
}

\author{
P. Oteiza ${ }^{1, *}$, S. Orozco ${ }^{2}$, M. Pérez ${ }^{2}$, C. Bedoya ${ }^{2}$, J. Neila² \\ ${ }^{1}$ Department of Physics, School of Architecture, Universidad Politécnica de Madrid, Spain \\ 2 Department of Construction, School of Architecture, Universidad Politécnica de Madrid, Spain \\ *Corresponding author: Tel: +34 913366542, Fax: +34 913366554, E-mail: mariapilar.oteiza@upm.es
}

\begin{abstract}
The objective of this paper is to present the computer simulation results that we have obtained with a new window design. This prototype is equipped with the elements necessary to capture and distribute natural daylight in an optimum way. The whole window system is able to be adapted to the weather conditions of most of the Iberian Peninsula. Its design contains elements to let the sunlight into the room, and elements to control it. The initial results of the daylight experimental analysis we have carried out so far, demonstrate the system's overall efficiency, however, we continue to research about the light shelf's optimal configuration in order to obtain the maximum and most flexible performance. There is demonstrated in this work that the Modular window with a top hollow of $40 \mathrm{~cm}$, instead of $30 \mathrm{~cm}$ of the original one, improves the luminous conditions of the room. Once the preliminary analysis phase is concluded, the window will be installed in one of the two testing houses being constructed at Cáceres (Spain), so that real-scale conclusions can be obtained, and recommendations be set, aimed to improve the quality of the construction process, while maintaining the high standards of sustainability we pursue.
\end{abstract}

Keywords: Windows, Daylighting, Solar Protection, Sustainability, Industrialization.

\section{Introduction}

This paper summarizes the design process, and the final results, for the development of a Modular window, capable of effectively responding to the climatic conditions of the Iberian Peninsula. It is part of the INVISO research project (Industrialization of Sustainable Housing) under development at the ETSAM (Escuela Técnica Superior de Arquitectura de Madrid). It is being carried out by the Researching Group ABIO (Bioclimatic Architecture in a Sustainable Environment).

The design process started off with the definition of the objectives that the Modular window must achieve, which at the same time, determined it's basic constitutive elements: a solar shading box, a light shelf for daylight projection into the inner parts of the room, direct light and solar radiation control elements, as well as phase change materials (PCM) for thermal lag profiting. With this basic component list, two 1:10 scale models were built and exposed to real external environmental conditions. Continuous light level measurements ${ }^{[1]}$ were taken with these models, which, along with thermal balance calculations ${ }^{[2]}$ and the simulations presented here, allowed us to correct of the original design until the current Optimized version. This Optimized Modular window consists of three vertically aligned apertures: the top one with a $0.40 \mathrm{~m}$ height and light shelf; the central one, with a $1.38 \mathrm{~m}$ height and low emissivity glazing; and the lower one with an $0.82 \mathrm{~m}$ height and an externally glazed Trombe wall with paraffin as PCM.

Partial prefabrication is intended to make the installation easier, and allow some flexibility in the aspect of the final result.

\section{Design objectives}

In order to reduce environmental impact associated with buildings envelope, external windows in medium latitude countries, as in the case of Spain, must keep a balance between 
daylight entry and it's implicated heat transfer ${ }^{[3,4]}$. The window must be industrializable, so its main elements will be pre-assembled in the factory and later brought to the building site. Materials employed will be light, safe, economic and, as far as possible, not aggressive with the environment.

The future objective of the present work is not only the prototype design, but it's construction and installation in a housing building which will be used as a laboratory. Monitored data from the different thermal and daylighting parameters will be compared to those obtained in an identical building with conventional windows, so that real conditions results and conclusions can be obtained from them. In Cáceres (39² 28' N and 405 m.a.s.l) far from big water masses which would mild the value oscillations, temperature fluctuations per day and per year are very important. In a summer day up to a $15{ }^{\circ} \mathrm{C}$ difference can be measured. Taking into account the annual behavior, external temperature differences can reach $25{ }^{\circ} \mathrm{C}$ between a summer and a winter day. These marked fluctuations require different strategies of environmental conditioning. In summary, it can be said that in Cáceres, like in Madrid, cities of soft and large winters, there's a need for a mechanical heating system during $73 \%$ of the annual period, furthermore, the short and strong summers require cooling during the $27 \%$ left. The dimensioning stage of the design process, has considered current regulations on daylight and ventilation minimal areas: the Modular Window has an area that accounts for the $22.30 \%$ of the test room's total floor area, which, by far, surpasses the value stated in the current regulation.

\section{Components}

The components that make this window an innovative product, Fig. 1, can be grouped in three zones: Upper zone or clerestory. It is $0.30 \mathrm{~m}$ high, its main function is to light the interior of the room by reflecting daylight on the shelf ${ }^{[5]}$. The light shelf is $0.9 \mathrm{~m}$ deep and it is covered on its upper side by a $90 \%$ reflectance mirror. The light shelf is partly inside the module (1/3 of its depth). The Central zone, or window view. It is $1.48 \mathrm{~m}$ high. Its main function is to allow observation and contact with the outside environment. It is also able to open and allow ventilation. And finally, the Bottom zone, $0.82 \mathrm{~m}$ high, and designed to integrate phase change materials in order to maximize thermal benefits. Besides, the Central zone and the Lower zone are surrounded by a frame which overhangs $0.6 \mathrm{~m}$ in order to reduce the direct sun radiation and also the diffuse sun radiation.

\section{Experimental analysis of the Modular Window's daylighting performance}

In the previously undertaken experimental study, two 1:10 scale models were used. These were situated on an obstacle-free (no overshadowing) terrace in Madrid. One of the models was equipped with a simplified Modular window, consisting of its three basic parts: top light shelf, central shaded opening, and lower completely opaque box. The second model was equipped with a conventional window, without the light shelf, nor any shading device. This was used as the reference model. Continuous measurements were taken, for global horizontal illuminance using five photometric sensors Li-Cor 210SA, two scenarios were tested: the first one, allowing light only through the top opening (clerestory only), and the second one, allowing illumination through both the top, and central openings (clerestory and view). Los the results are summarized in the following statements:

- With the top section opened (clerestory), and the rest of the window shut (opaque), the sensor located furthermost from the window, registered higher illuminance values for the Modular window, during $75 \%$ of the time. Reaching a maximum difference value of 1.87 times in a Modular - Conventional comparison. Therefore, the light shelf on 
the Modular window significantly contributed to a better illumination of the inner room area farther from the window.
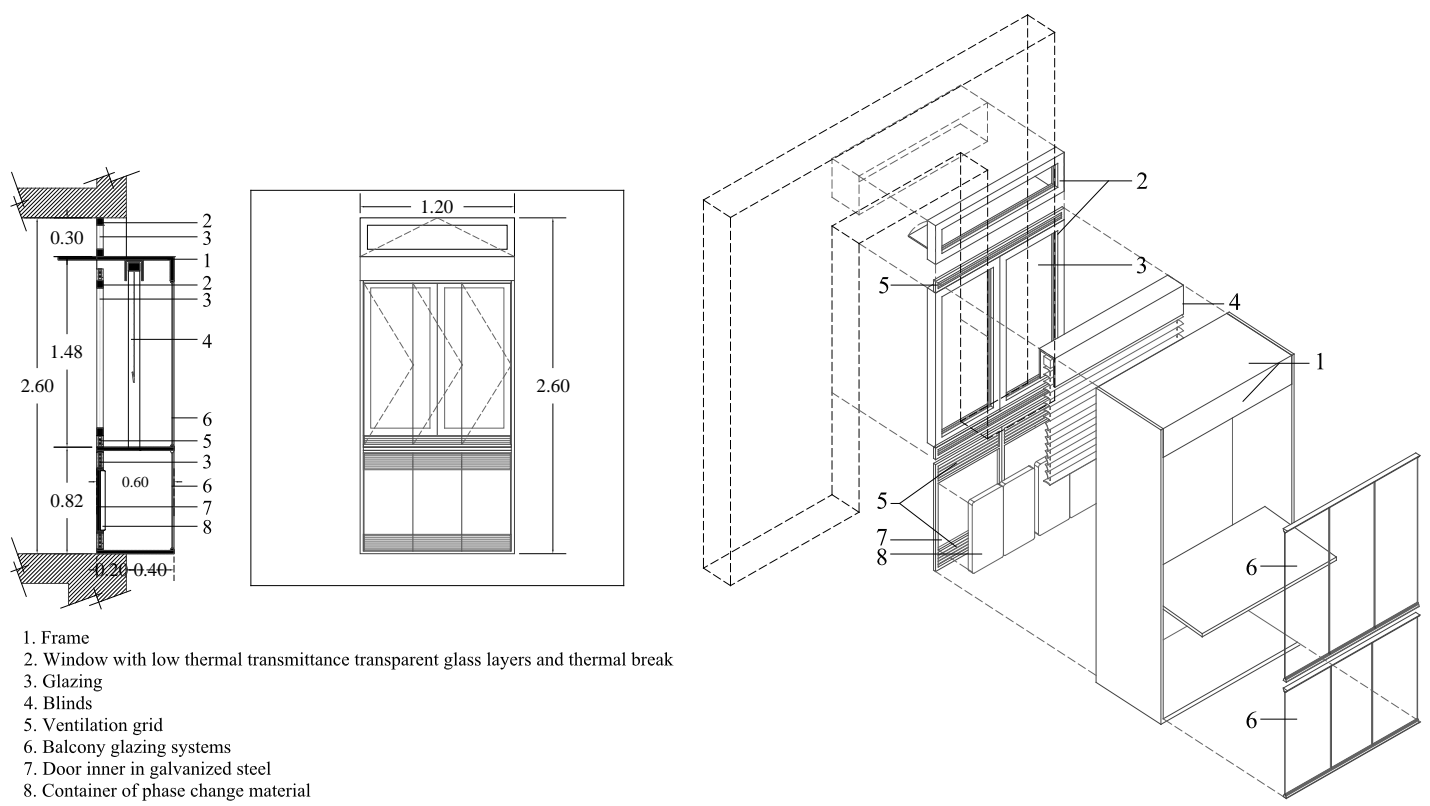

Fig. 1. The components of the original Modular Window

- When the two upper sections of the window (clerestory and view) were open on both models, the inner sensor (furthermost from window), registered higher illuminance levels for the Modular window during 21\% of the time. The difference with the result mentioned on the previous statement is due to the effect of the solar shading box on the Modular window.

- The Modular Window improved the lighting conditions in the area closest to the window because the solar shading reduced the high illuminance values of that particular zone (especially during summer's high solar angle period).

- The differences in illuminance levels obtained with the sensors located near and far from the window, were smaller in the Modular window equipped model. This demonstrates a more uniform daylight distribution in the room's interior, and thus a significant glare reduction.

\section{Clerestory modifications for the optimization of the Modular window}

The study described so far, corresponds to the basic design of the Modular window, which had a $30 \mathrm{~cm}$ high top opening (clerestory). In order to improve the previously obtained results, we have carried out a brief comparative analysis with a variable clerestory dimension, ranging from 30, 35, 40, and $45 \mathrm{~cm}$, Fig. 2. This range is derived from the limits established as acceptable: for starters a vertical dimension less than $30 \mathrm{~cm}$ is not constructively or functionally possible; on the other hand, the light shelf's vertical position must correspond to a certain height that does not cast any direct reflexion at the occupant's eye level. Accordingly, with a $45 \mathrm{~cm}$ clerestory, the light shelf sits at a top height of $215 \mathrm{~cm}$ from the floor, which is enough to avoid any light reflexion related disturbances. This analysis has been developed with the use of the simulation tools Autodesk Ecotect, and LBNL Radiance ${ }^{[6]}$. In the first place, the annual periods with different thermal requirements have been defined, and consequently, their relationship with the window design. Based on the climatic records from the Spanish Weather for Energy Calculations (SWEC) ${ }^{[7]}$ for the city of Madrid (very similar conditions to the ones found at Cáceres) and with the use of the Adaptive Comfort 
Chart, developed by J. Neila, and his research group at ETSAM ${ }^{[8]}$, we have defined a basic human comfort temperature range that goes from $18^{\circ} \mathrm{C}$ up to $26^{\circ} \mathrm{C}$.
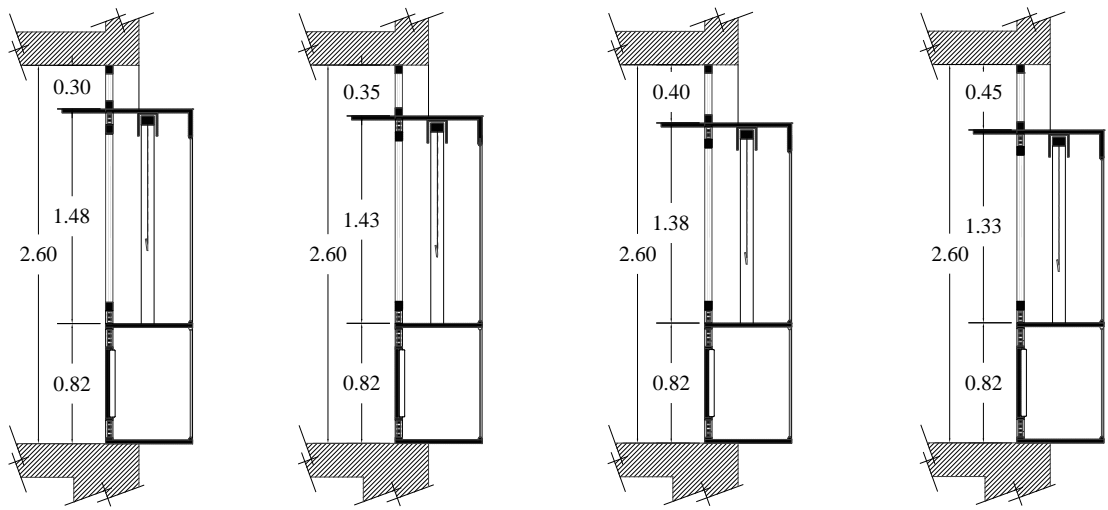

Fig. 2. Detail sections of the four dimensioning options analyzed for the clerestory(dimensions in $m$ ).

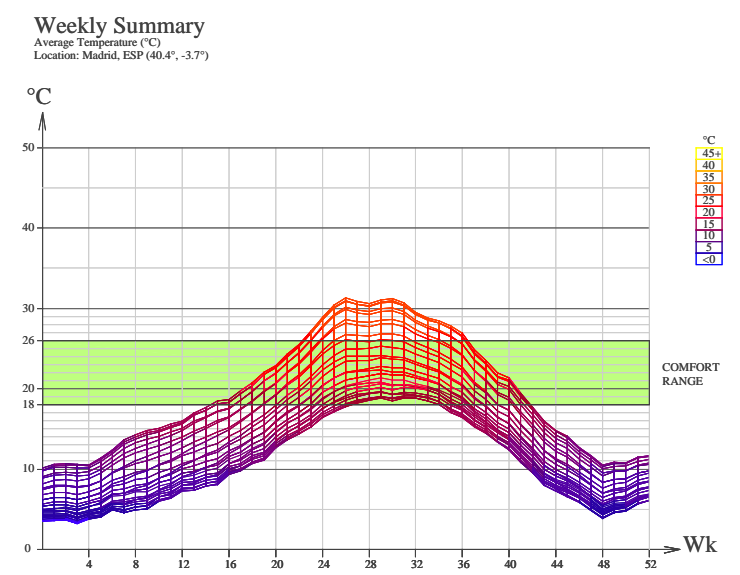

Fig. 3. Average temperature trend and human comfort range for the city of Madrid.

From here, the annual period with average temperature values under $18{ }^{\circ} \mathrm{C}$, has been established as "Heating Requiring Period", and inversely, the period with average temperature values over $26^{\circ} \mathrm{C}$, has been defined as "Cooling Requiring Period". Fig. 3 shows the average temperature trend throughout the year, along with the previously mentioned comfort range. Fig. 4 shows the monthly heating/cooling requirements as well as the solar radiation available so as to clearly observe each period and its thermal requirements. With the start-end dates established for each period, the clerestory's dimension was analyzed so that it would allow the maximum collect of direct solar radiation during the underheated period, but at the same time, it would offer the maximum protection from possible heat gains during the overheated period.

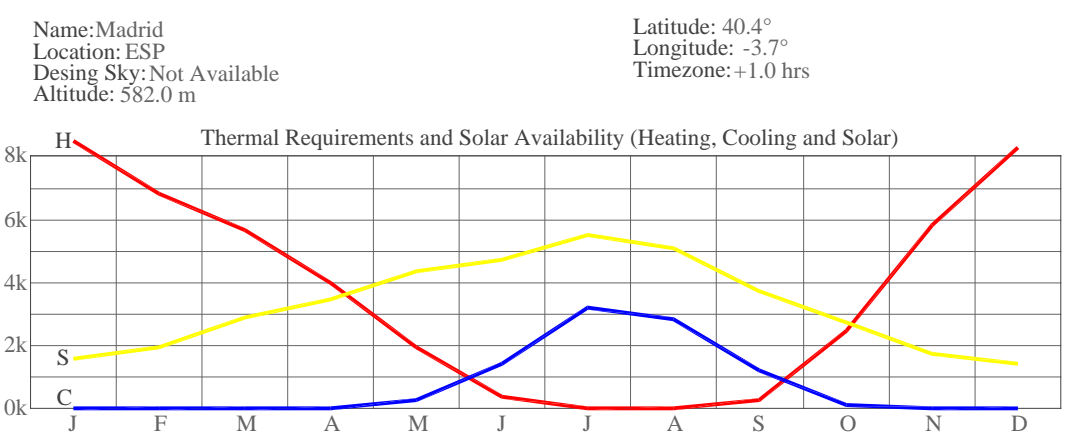

Fig. 4. Thermal requirement curves (heating: red ; cooling: blue) and solar availability (yellow) for the city of Madrid. 


\subsection{Shading coefficient analysis}

In order to optimize the clerestory dimensions and ensure the light shelf's máximum efficiency, the following premise has been set: a very small opening, offers a good protection (shading) during the overheated period, but limits the thermal contribution of solar direct radiation during the underheated period; in an opposite way, a very big opening maximizes thermal benefits during this cold period, but also contributes to interior space overheating during the warm period. To be able to objectively compare this factor, we have analyzed the Shading Coefficient value, which has been defined by the australian research group SquareOne ${ }^{[9]}$ as: "...an hourly averaged value that represents the shaded area of a vertical opening in relationship to the opening's total area ". The values of each dimensioning option have been studied considering a minimum inset of $18 \mathrm{~cm}$ (typical value of an unshaded window built with a conventional system). Fig.5 shows the respective performance in terms of the capture/protection balance described above. Amongst the multiple interpretations that can be made, the one we are more interested in is the one related to each of the openings behavior during the warm and cold periods. For instance, it is clear that all of the openings offer $100 \%$ shading during May, June, and July, however, the $45 \mathrm{~cm}$ opening considerably loses effectiveness during August and September, at a monthly ratio slightly superior to $15 \%$. In a similar way, the original $30 \mathrm{~cm}$ opening minimizes the heat gain profits during the cold period, with a minimal shading coefficient of $30 \%$ year-round. For these particular reasons we have focused on the $35 \mathrm{~cm}$ and $40 \mathrm{~cm}$ openings, of which a very similar performance can be apreciated. Nonetheless, the $40 \mathrm{~cm}$ hole has an average shading coefficient $3 \%$ smaller than the $35 \mathrm{~cm}$ hole one during the underheated period of the year (months with heating requirements). This results in a slightly better solar-thermal energy penetration and minor savings in heating-energy. Hence, the $40 \mathrm{~cm}$ hole has been selected to undertake the daylighting performance simulation analysis.

\subsection{The use of Ecotect/Radiance for daylight simulation.}

Having selected the optimized dimensions for the clerestory $(40 \mathrm{~cm})$, and keeping the original design dimensions $(30 \mathrm{~cm}$ ) as a reference, we carried out computational daylight simulations of interior luminous distribution. Furthermore, in order to visually determine the advantages of the proposed design, we have compared both Modular windows (original and optimized) with a conventional window. The simulation has been done using a software combination of Autodesk Ecotect + LBNL Radiance, and therefore all of the results obtained are subject to the accuracy and acknowledgement of these programs. All of the analysis have been undertaken in an hourly sequence, the luminous internal penetration and distribution results are presented for 13h (legal time), and accordingly there are three images for each date.

Fig. 6 shows the illuminance range for a date representative of the underheated period: December $21^{\text {st }}$ (winter solstice). There are no remarkable differences between the three models (Conventional, Modular, and Optimized Modular), mainly due to the low angular rise of solar rays $\left(23^{\circ}\right.$ at noon $)$. 


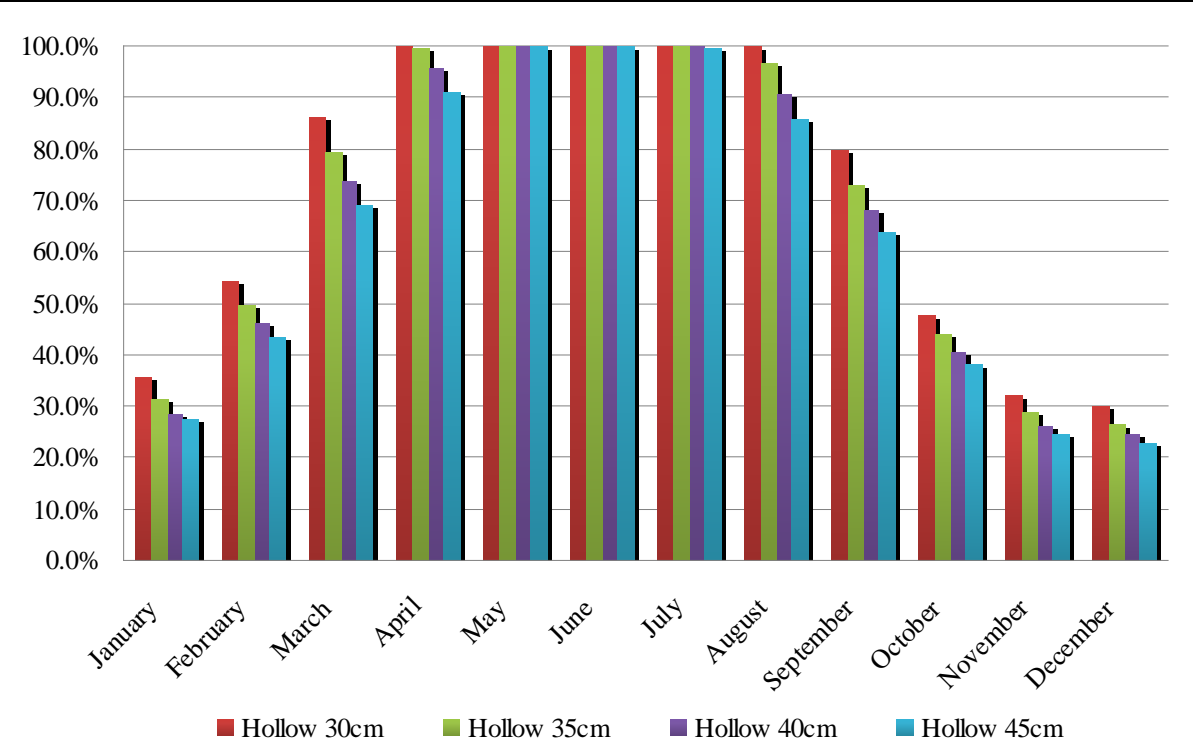

Fig. 5. Monthly shading coefficients comparison for the four dimensioning options.

The conventional window (on the left) shows the highest illuminance levels both during morning and evening hours, plus, it performs similarly to the Modular (center) and Optimized Modular (right) models during midday. In spite of this, a slightly better performance (more depth) can be observed for the Optimized Modular against the original design.

Fig. 7, shows the same analysis done for a date representative of the overheated period: June 22 (summer solstice). For this second series of analysis, a better performance on behalf of the Optimized Modular Window becomes quite evident: a deeper luminous penetration, along with a more uniform light distribution, and mainly a better shading protection against direct solar radiation during all day.

Finally, the last analysis series correspond to a "thermal neutrality" date: September 21 (fall equinox), Fig. 8. Clearly demonstrates the functioning of the three window models in a moderate solar height scenario. On top of a better overall illumination, the Optimized Modular Window offers the best shading against direct solar radiation and thus, it avoids as much as possible the potential glare effect.

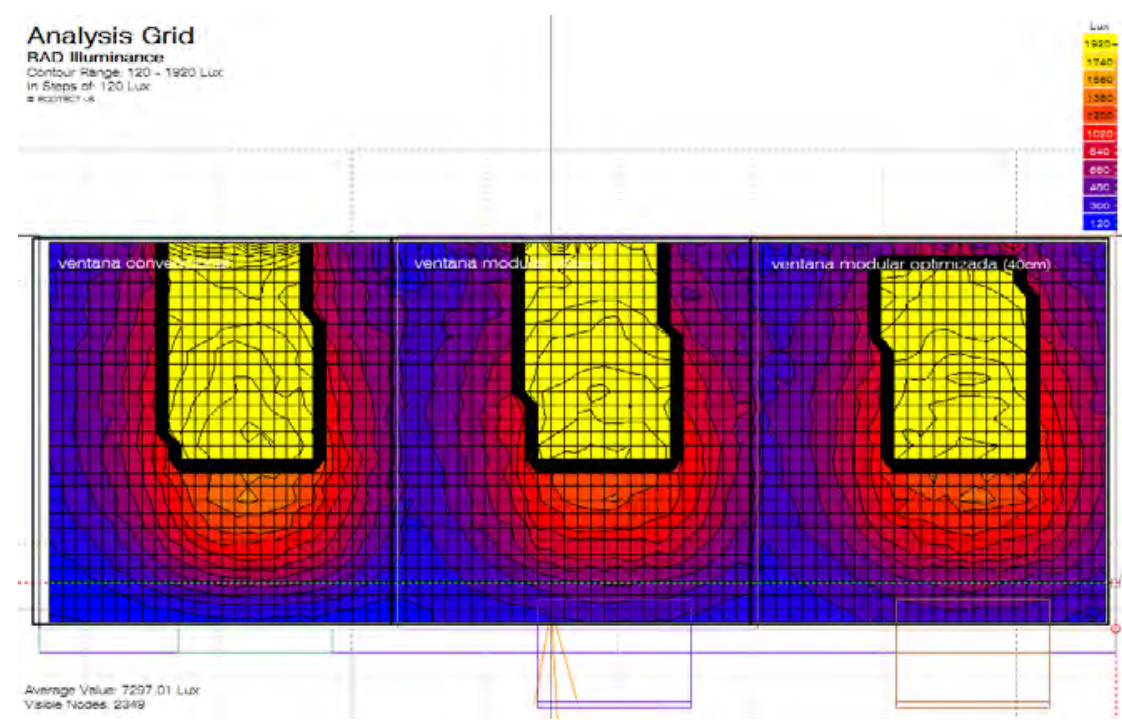

Fig. 6. Internal illuminance distribution (plan view of the room) for the three window: Conventional (left), Modular original (center), Modular optimized (right), during December $21^{\text {st }}$ at $13 \mathrm{~h}$. 


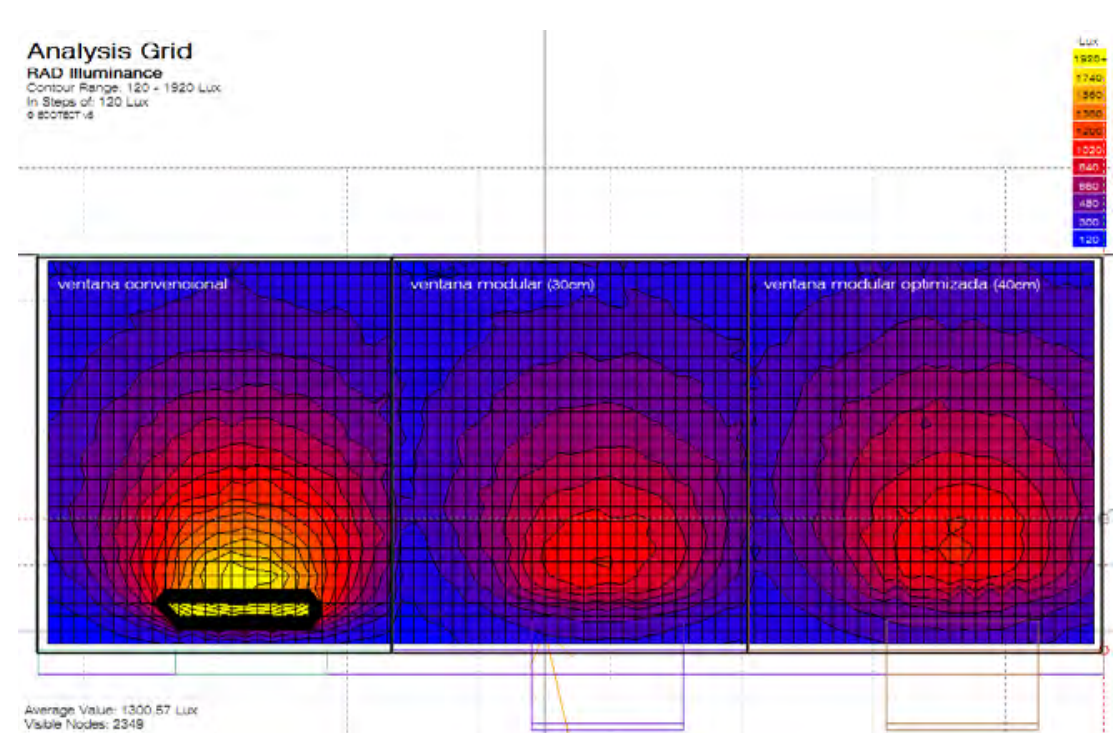

Fig. 7. Internal illuminance distribution (plan view of the room) for the three windows: Conventional (left), Modular original (center), Modular optimized (right), during June $22^{\text {nd }}$, at $13 \mathrm{~h}$.

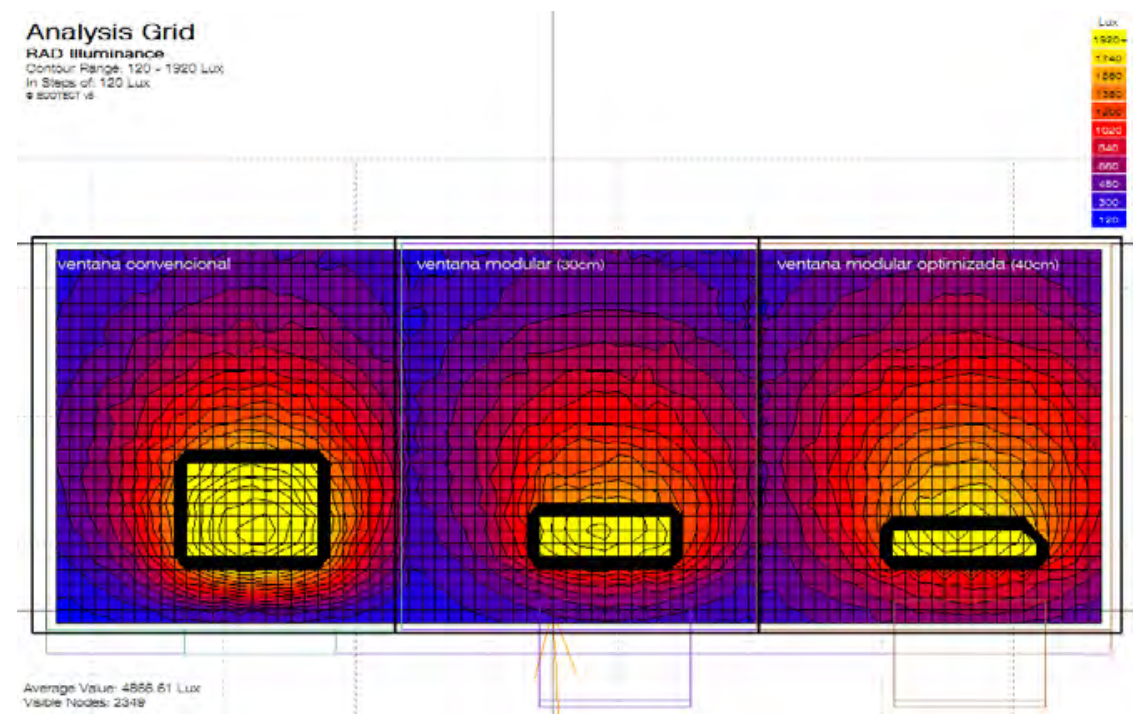

Fig. 8. Internal illuminance distribution (plan view of the room) for the three windows: Conventional (left), Modular original (center), Modular optimized (right), during September $21^{\text {st }}$ at $13 \mathrm{~h}$.

\section{Conclusions}

The Modular window consists of three parts: i) the top section, which is a $30 \mathrm{~cm}$ high opening equipped with a light shelf to improve the illumination of the inner room area, farthest from the window: ii) the central section, with a $148 \mathrm{~cm}$ high opening that not only pursues natural illumination and visual contact with the exterior surroundings, but also counts with the protective shading elements required by our climatic conditions; and iii) the lower section is an opaque, $82 \mathrm{~cm}$ high element, that includes a trombe wall formed out of paraffin, which is an innovative building material that changes its physical state (solid-liquid) at specific predetermined temperatures, thus reducing and retarding the heat exchange through itself. In order to be able to test its luminous performance, a previous study was made with the use of scale models, for which the Modular window design was compared against a conventional unequipped window; this study demonstrated that the Modular window improved daylighting intensity in the inner part of the room, located farther from the window. However, since the 
experimental study advanced very slowly, and was too dependent to the highly variable environmental conditions (i.e. cloud cover), we set to study the modification of the upper opening and its light shelf, with the use of photometric simulation tools: specifically the combination of analysis programs Autodesk Ecotect + LBNL Radiance. Four dimensioning possibilities for the upper opening were tested: the original $30 \mathrm{~cm}$ height, plus another three: 35,40 , and $45 \mathrm{~cm}$. The four options provided a protection of $100 \%$ from solar direct radiation during the first three months of the overheated period (May, June, July), however the $45 \mathrm{~cm}$ opening considerably lost its protective effectiveness during the months of August and September, at a monthly rate slightly superior to $15 \%$. In a similar way, but during the underheated period, the $30 \mathrm{~cm}$ opening was too limiting on the required solar heat reception, as its shading coefficient didn't go under the $30 \%$ value during any month of the year. A very similar behavior was appreciated with the 35 and $40 \mathrm{~cm}$ openings. Nonetheless, and although it was only by a small difference, the $40 \mathrm{~cm}$ opening performed $3 \%$ better to the thermal requirements of the cold period. Taking into account the balance between solar heat profiting, and excess direct radiation shading, during the two annual periods with heating and cooling requirements, the analysis results are that the $40 \mathrm{~cm}$ opening performed better, hence, it has been proposed as the new dimension to use with the Optimized Modular window design. It has been demonstrated that the Optimized Modular window produces the best overall daylight conditions in the interior of the room, because it improves the illuminance levels on the deeper area (far from the window), contributes to a more uniform light distribution, and at the same time protects from overheating and potential glare effect.

\section{References}

[1] P. Oteiza; M. Pérez; C. Bedoya; J. Neila; Modular window daylighting performance vs. Conventional window, Lighting Research and Technology (in approval process).

[2] P. Oteiza; C. Pérez; M. Pérez; Modular window thermal performance vs. Conventional window, Energy and Buildings (in approval process).

[3] D. Phillips, Daylighting: Natural Light in Architecture, Architectural Press, London (2004).

[4] P. Poyce, C. Hunter, O. Howlett, The Benefits of Daylight through Windows, Rensselaer Polytechnic Institute, New York (2003)

[5] A. Soler, P. Oteiza, Lightshelf Performance in Madrid, Spain, Building and Environment 32 (1997) 87-93.

[6] Natural Frequency Online Community; wiki.naturalfrequency.com; archive site for autodesk ecotect analysis educational resources; consulted on August 2010.

[7] Grupo de Termotecnia de la Escuela Superior de Ingenieros de Sevilla; Agencia Estatal de Meteorología; Spanish Weather for Energy Calculations SWEC, Seville, Spain (2008)

[8] J. Neila, Arquitectura Bioclimática en un Entorno Sostenible, Editorial Munilla-Lería, Madrid 2004.

[9] A.J. Marsh, Square One research, University of Western Australia (2008). 